\title{
A Matter of Life and Death: Alternative Stable States in Trees, From Xylem to Ecosystems
}

\section{OPEN ACCESS}

Edited by:

Giovanna Battipaglia, University of Campania Luigi Vanvitelli,

Italy

Reviewed by:

Bruno O. Gimenez,

Smithsonian Tropical Research

Institute (Panama), Panama

Tamir Klein,

Weizmann Institute of Science, Israel

*Correspondence:

William M. Hammond

william.hammond@okstate.edu

Specialty section:

This article was submitted to

Forest Ecophysiology,

a section of the journal

Frontiers in Forests and Global

Change

Received: 08 May 2020

Accepted: 09 November 2020

Published: 30 November 2020

Citation:

Hammond WM (2020) A Matter

of Life and Death: Alternative Stable

States in Trees, From Xylem

to Ecosystems.

Front. For. Glob. Change 3:560409.

doi: $10.3389 / f f g c .2020 .560409$

\section{William M. Hammond*}

Department of Plant Biology, Ecology, and Evolution, Oklahoma State University, Stillwater, OK, United States

Global forests are experiencing widespread climate-induced mortality. Predicting this phenomenon has proven difficult, despite recent advances in understanding physiological mechanisms of mortality in individual trees along with environmental drivers of mortality at broad scales. With heat and drought as primary climatic drivers, and convergence on hydraulic failure as a primary physiological mechanism, new models are needed to improve our predictions of Earth's forests under future climate conditions. While much of ecology focuses on equilibrium states, transitions from one stable state to another are often described with alternative stable state theory (ASST), where systems can settle to more than one stable condition. Recent studies have identified threshold responses of hydraulic failure during tree mortality, indicating that alternative stable states may be present. Here, I demonstrate that the xylem of trees has characteristics indicative of alternative stable states. Through empirical evidence, I identify a catastrophic shift during hydraulic failure which prevents trees from returning to pre-droughted physiological states after environmental stressors (e.g., drought, heat) are relieved. Thus, the legacy of climate-induced hydraulic failure likely contributes to reduced resilience of forests under future climate. I discuss the implications and future directions for including ASST in models of tree mortality.

Keywords: drought, ecophysiology, tree mortality, xylem, alternative stable states

\section{INTRODUCTION}

"All that lives must die," wrote Shakespeare in Hamlet, "passing through nature to eternity." Indeed, most all individuals eventually cease living - with only one of Earth's estimated $>8$ million species found to be biologically immortal (Mora et al., 2011; Lisenkova et al., 2017). Organisms exist then in a chaotic state-persisting against the eventuality of death. Of life on Earth, individuals escaping death the longest are trees. Methuselah (a bristlecone pine, Pinus longaeva), is the oldest living individual-estimated to be 4,850 years old (Salzer et al., 2019). Despite the ability of individual trees to escape death for millennia, widespread climate-induced mortality of trees in recent decades has become a global concern (Allen et al., 2010). Every forest-bearing continent experienced climate-induced (associated with drought, heat, or both) tree mortality events-with effects ranging from canopy thinning to the transition of entire ecosystems to a non-forested state (Allen and Breshears, 1998; Scheffer et al., 2001; Allen et al., 2010; Gonzalez et al., 2010; Choat et al., 2012). As loss of forest cover corresponds to a loss of important ecosystem services such as carbon 
storage, biodiversity richness, and climate regulation (Foley, 2005), understanding conditions and mechanisms of tree mortality has been a focus of research at scales from individual trees to the entire planet (Brodribb and Cochard, 2009; Barigah et al., 2013; Allen et al., 2015; Hammond et al., 2019).

Across global forests, observations have converged on the physiological process of hydraulic failure as ubiquitous in climate-induced tree mortality (Adams et al., 2017). Hydraulic failure occurs when water under tension in the xylem becomes occluded by air emboli, interrupting transport of water and potentially resulting in whole-tree desiccation from which it is impossible to recover, e.g., death (Cochard and Delzon, 2013). Recent work has identified a threshold-like response between hydraulic failure and mortality, including direct quantification of a lethal dose of hydraulic failure in tree species for the first time (Urli et al., 2013; Hammond et al., 2019). While hydraulic failure has been ubiquitously associated with droughtinduced mortality, other important agents of mortality include windthrow, lightning, and associated crown damage from storms (Negrón-Juárez et al., 2010; Fontes et al., 2018; Arellano et al., 2019; Yanoviak et al., 2020). Hotter droughts can induce leaf senescence via oxidative stress, leading to rapid canopy collapse (Matusick et al., 2013; Jardine et al., 2015). Finally, biotic agents (e.g., bark beetles, fungal pathogens) may drive drought- and heat-stressed trees to the breaking point (Cobb et al., 2012; Anderegg et al., 2015). While the complex and interactive effects of these multiple agents are not considered here, their amplification of tree mortality is likely to accelerate under further anthropogenic warming and drought (Allen et al., 2015).

Existing tree mortality frameworks include that of McDowell et al. which considers the physiological trade-off between hydraulic failure and so-called "carbon starvation," when a tree exhausts available carbon to meet maintenance respiration during sufficiently long, source-limiting droughts (McDowell et al., 2008). Others have quantified environmental signals to predict mortality (Hogg et al., 2008; Phillips et al., 2009), without explicitly considering the role of physiological responses to environment, while more recent attempts have combined environmental signals with physiological responses (Breshears et al., 2005; Anderegg et al., 2012; Schwantes et al., 2016; Johnson et al., 2018). With an aim toward anticipating ecosystem shifts and management actions which might promote or inhibit these changes, state-and-transition models have been developed for managing forests following die-off events (Cobb et al., 2017). Whatever the framework, all have included the concept of thresholds - that there exist conditions beyond which it becomes more likely trees will die, than survive. Despite these advances, the ability to predict mortality at any scale (and especially, across scales) remains a grand challenge for Ecology. It is natural then to ask-what improvements can be made in our ability to predict when a tree, stand, or entire forest is likely to die?

Transitions in ecosystems have long been investigated through alternative stable states theory (ASST) (Holling, 1973; May, 1977; Scheffer et al., 2001). While threshold responses such as those observed during climate induced tree mortality are an indicator that a system may have more than one stable state-other criteria must also be met. Alternative stable states for a system exist only if that system can settle to alternative states under the same external conditions (Scheffer, 2009a). What are the applications, limitations, and extensions of our understanding that can be brought to bear by considering climate-induced tree mortality through the lens of ASST? First, I must acknowledge that ASST has already been used to investigate vegetation shifts at the ecosystem level for some time. Observations in the west African Sahel have shown that communities of woody vegetation show clear signs of having alternative stable states-oscillating at multidecadal periods between savannah and forested states that track with changes in regional climate (Scheffer et al., 2001; Gonzalez et al., 2010). Here, I propose the application of ASST to the xylem tissue of trees, and implications of such an ASST approach to individuals and higher levels of ecological organization.

\section{BRIEF REVIEW OF ALTERNATIVE STABLE STATES (ASST) CONCEPTS}

First, a few definitions should be established with which we can discuss ASST in the context of a single tree. Attractors can be defined as a single state toward which a system can converge and may include cycles or stable points; in ball and hill models the valleys/basins are stable attractors, or states, and the depth of these basins indicates how resilient they are to shifts. Catastrophic shifts occur when some minor change at a critical point (the so-called tipping point, or catastrophic bifurcation) shifts a system from one attractor to an alternative attractor. These catastrophic shifts are unidirectional, such that hysteresis exists and transitions between two stable states require an unequal change in external conditions. These concepts are visually communicated via stability landscapes, using a ball to represent the ecosystem's present state, basins as attractors, and hills as tipping points (as later in this paper, in Figures 1, 2). While these brief definitions suffice for the present paper, I refer readers interested in a deep review of these concepts to Scheffer (2009b).

\section{XYLEM AS A STUDY SYSTEM}

From embryogenesis through reproductive maturity, trees have a remarkable diversity of forms and functions, all of which depend upon the availability of water (Givnish, 1979, 2002). Within a single tree, connected cell types, tissues, and organs carry out many processes necessary for survival, growth, and reproduction of the whole organism (Holbrook and Zwieniecki, 2011). Of Earth's diverse plant forms, trees are best distinguished by their xylem. This extensive secondary woody tissue functions in mechanical support-responsible for trees being the tallest, and also the largest (by volume) organisms on the planet (Hacke and Sperry, 2015), leading to their dominance in global estimates of biomass (Bar-On et al., 2018). More than just a scaffold, xylem conducting large volumes of water across long distances efficiently (Tyree and Zimmermann, 2013), at minimal energy costs operating under cohesion-tension, was critical to the development of trees as a life form on Earth 

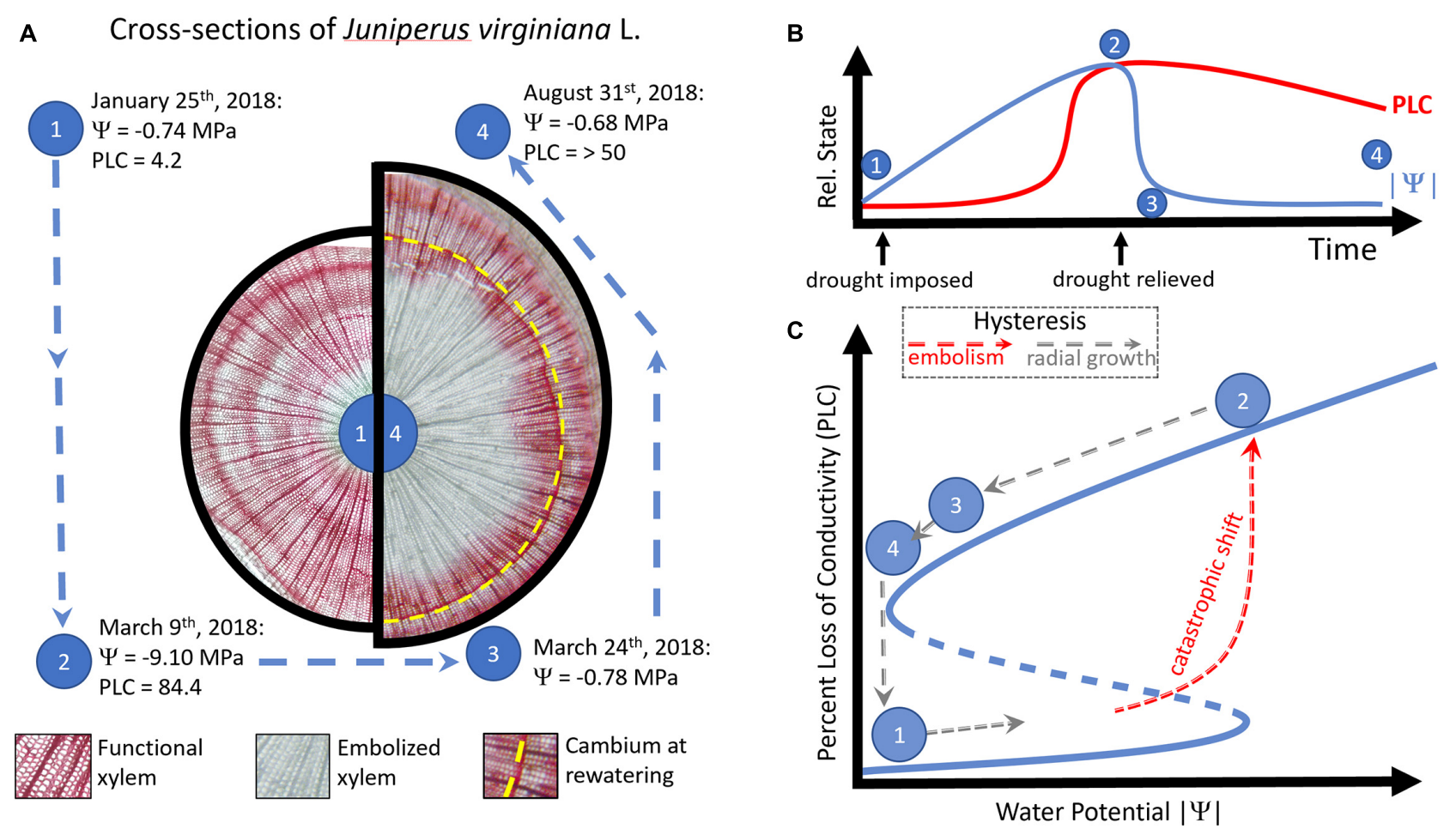

FIGURE 1 | In panel (A), cross-sections taken from a single Juniperus virginiana L. tree at time point (1) and (4) are shown on the left and right, respectively. Physiological measures of drought stress ( $\Psi$, percent loss of conductivity-PLC) are shown for four time points during the drought-rewatering experiment from the same tree (points 1-4, data from Hammond et al., in prep). Panel (B) shows the relationship between the relative state of PLC (red line) or the absolute value of water potential $(|\Psi|$, blue line) during the duration of the experiment. While $|\Psi|$ rapidly resumes the pre-drought condition after drought is relieved, PLC remains high as the xylem is in an alternative stable state. The transition between (1) and (2) is shown in panel (C) as a catastrophic shift, where once a large portion of the xylem is embolized, function cannot be restored by the simple relaxation of xylem tension. Arrows indicate the direction of hysteresis, with counterclockwise arrows indicating hysteresis. Red arrows represent a catastrophic shift to an alternative, embolized stable state, which requires radial growth (gray arrows) to return to the previous state.

(Dixon and Joly, 1894). For an individual tree, xylem function is central to growth, survival, and reproduction (Hacke and Sperry, 2015). As hydraulic failure of xylem has been identified as one of the most important agents in climate-driven tree mortality (Adams et al., 2017; Brodribb et al., 2020), I will demonstrate the characteristics of xylem physiology which make it suitable for the application of ASST.

\section{WHOLE-PLANT XYLEM AS A SYSTEM WITH ALTERNATIVE STABLE STATES: CASE STUDY IN JUNIPERUS}

Xylem is composed of vascular elements (in Angiosperms) and tracheids (in gymnosperms, and in combination with vessels in some angiosperms) which are dead at functional maturity (Holbrook and Zwieniecki, 2011). During drought, the combination of increased atmospheric demand for moisture and decreased soil water availability creates tension in the xylem's water column, a force quantified as water potential (Scholander et al., 1965; Breshears et al., 2013). Considering water potential (hereafter, $\Psi$ ) as an external condition to the system of xylem, we can acknowledge that as $\Psi$ declines (becomes more negative), tension $(|\Psi|)$ builds to the point that eventually, embolism is seeded into the xylem and begins to spread, occluding water transport (Sperry and Tyree, 1988; Cochard et al., 1992). While debates are ongoing regarding the capacity of xylem to refill (Klein et al., 2018; Lamarque et al., 2018), in this paper I provide observations from a manipulative experiment showing that trees which survived extreme hydraulic failure, eventually restored function via radial growth-a lengthy process - and did not refill appreciable amounts of embolized xylem.

What evidence qualifies xylem as a system which possesses alternative stable states? The first evidence that xylem has more than one alternative stable state, is that hydraulic failure occurs over a relatively narrow range of water potentials, resulting in typical "s-shaped" vulnerability curves with sharp transitions between near zero and near complete embolism of xylem (Cochard et al., 2005). Threshold-like responses are an indicator of alternative stable states within a system (Scheffer, 2009a), but alone are insufficient to indicate the existence of alternative stable states (Scheffer, 2009b). In addition to a threshold-like response, it must be possible for the system (here, xylem hydraulic function) to stabilize in alternate states under similar external conditions (here, $\Psi$ ). Using observations from a recent empirical study, I demonstrate that hydraulic failure not only shows a 


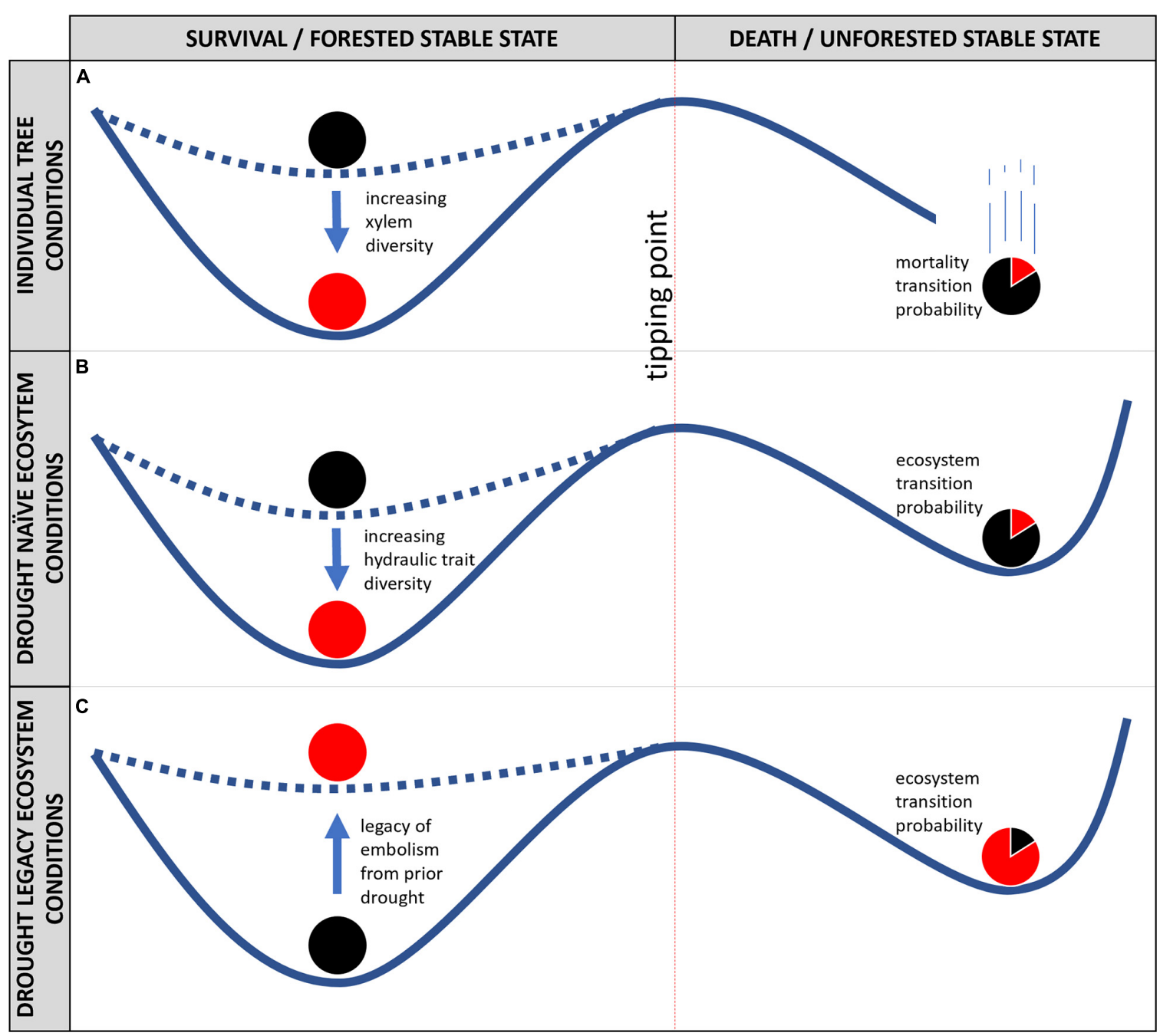

FIGURE 2 | Stability landscape models for an individual tree (A), drought naive ecosystems (B), and drought legacy ecosystems (C), with tree or ecosystem state on $x$-axis, and conditions on the $y$-axis. The tipping point between survival and permanent death of an individual tree (A), and for forest die-off of an ecosystem (B,C) is represented by a dashed red line. The depth of basins of attraction to the left of the tipping point can increase from shallow (low resilience, black ball) as diversity in hydraulic traits within an ecosystem (as in B), (or within a tree, xylem anatomical heterogeneity, as in $\mathbf{A}$ ) increases (high resilience, red ball). To the right of the tipping point, the proportional shading of the ball illustrates that it is less likely a resilient system would transition from forest to non-forest, relative to a less hydraulically diverse system (or tree). In (C), the legacy of hydraulic failure decreases ecosystem resilience (red ball), and ecosystem transition probability to a non-forested state is thus increased.

threshold response, but also catastrophic shifts to alternative stable states in the xylem of trees.

In a greenhouse experiment, I imposed drought on reproductively mature Juniperus virginiana L. (family Cupressaceae) in pots. Withholding water until pre-assigned targets of water potential, I monitored trees for death or survival after relieving drought. Prior to the onset of drought, I conducted active xylem staining to identify which xylem in the tree was functioning and found across the population (42 trees) that nearly all the xylem was functional (stained red, as in Figure 1A, left side). By comparison, I present a similar active xylem stain taken at the end of a full growing season's recovery (Figure 1A, right side) from the same tree, which survived a minimum tension of $<-9 \mathrm{MPa}$, resulting in $>84 \%$ loss of conductivity (hereafter, PLC). Substantial radial growth (tissue produced past the position of the vascular cambium at drought's maximum, Figure 1A, dashed yellow line) was required to restore conductivity of the woody tissue and embolism remained even 5 months after water potentials returned to pre-drought conditions (Figure 1A, right side). Despite returning to the pre-drought state in xylem tension, the system state of hydraulic failure lingered-demonstrating that a hysteresis exists between the alternative states of fully functional xylem, and xylem having experienced extreme hydraulic failure (Figure 1B). Consequently, when changes in $\Psi$ during drought led to a state shift (from functional, to embolized xylem), a return to the $\Psi$ associated with function (a water potential near zero) was not accompanied by restoration of xylem function. 
This meets the qualifications of a catastrophic shift, as there is hysteresis-conductivity of water through the xylem cannot resume its prior state, even though the external condition (xylem tension, $|\Psi|$ ) has returned to initial conditions (Figure 1C).

\section{RESILIENCE: FROM XYLEM TO INDIVIDUAL TREES TO COMMUNITIES}

While xylem possesses alternative stable states, the same concept cannot be applied to the "life or death" of an individual tree. As illustrated in Figure 2A, death of an organism does not represent an alternative state, but rather a terminal one. Once an organism is committed to death (e.g., past the tipping point in Figure 2A), it leaves the stability landscape-and cannot return. Thus, once whole-organism death occurs, it is best described as an irreversible threshold transition, without an alternative stable state (Scheffer, 2009b). On the other hand, trees may dieback at extremities - fusing off fine roots and terminal branches due to excessive embolism limiting available water to canopy function (Johnson et al., 2016; Jump et al., 2017). In the context of stability landscapes, mortality can be represented as a cliffonce the organism passes the tipping point, it is committed to death (Figure 2A). It is important to mention, that the concept of resilience can and should be invoked regarding hydraulic function and failure in the xylem of trees. Increasing diversity of the xylem network (e.g., broad vessel, tracheid, or pit size distributions, or inclusion of hyper-embolism-resistant vasicentric tracheids, as in many Mediterranean plants) will increase the strength of the attractor of hydraulic function (Carlquist, 1985). Species of trees surviving in some of Earth's driest habitats have accomplished such a feat by including both efficient (yet vulnerable to embolism) vessel elements and less efficient (yet safer from embolism) vasicentric tracheids in their xylem anatomy (Carlquist, 1985), such that a much broader range of water potentials must be experienced in order to induce a system-wide catastrophic shift (Figure 2A). Increasing xylem anatomical diversity within an individual tree is thus expected to increase resilience (Figure $\mathbf{2 A}$, red ball), reducing the probability of a transition to mortality.

In contrast to the outcomes of individual trees, potential outcomes at population and community levels include alternative stable states (Figures 2B,C). Communities of trees display remarkable diversity in hydraulic traits, such as the water potential corresponding to $50 \%$ loss of conductivity in the xylem (P50). For example, global observations have shown that P50 can vary within a biome by up to an order of magnitude, while across biomes the median value of P50 is relatively stable (McCulloh et al., 2019). Furthermore, traits like P50 seem to be conserved within lineages of plants (Maherali et al., 2004; Sanchez-Martinez et al., 2020) indicating that biodiversity of species and higher taxonomic orders within a forest correspond

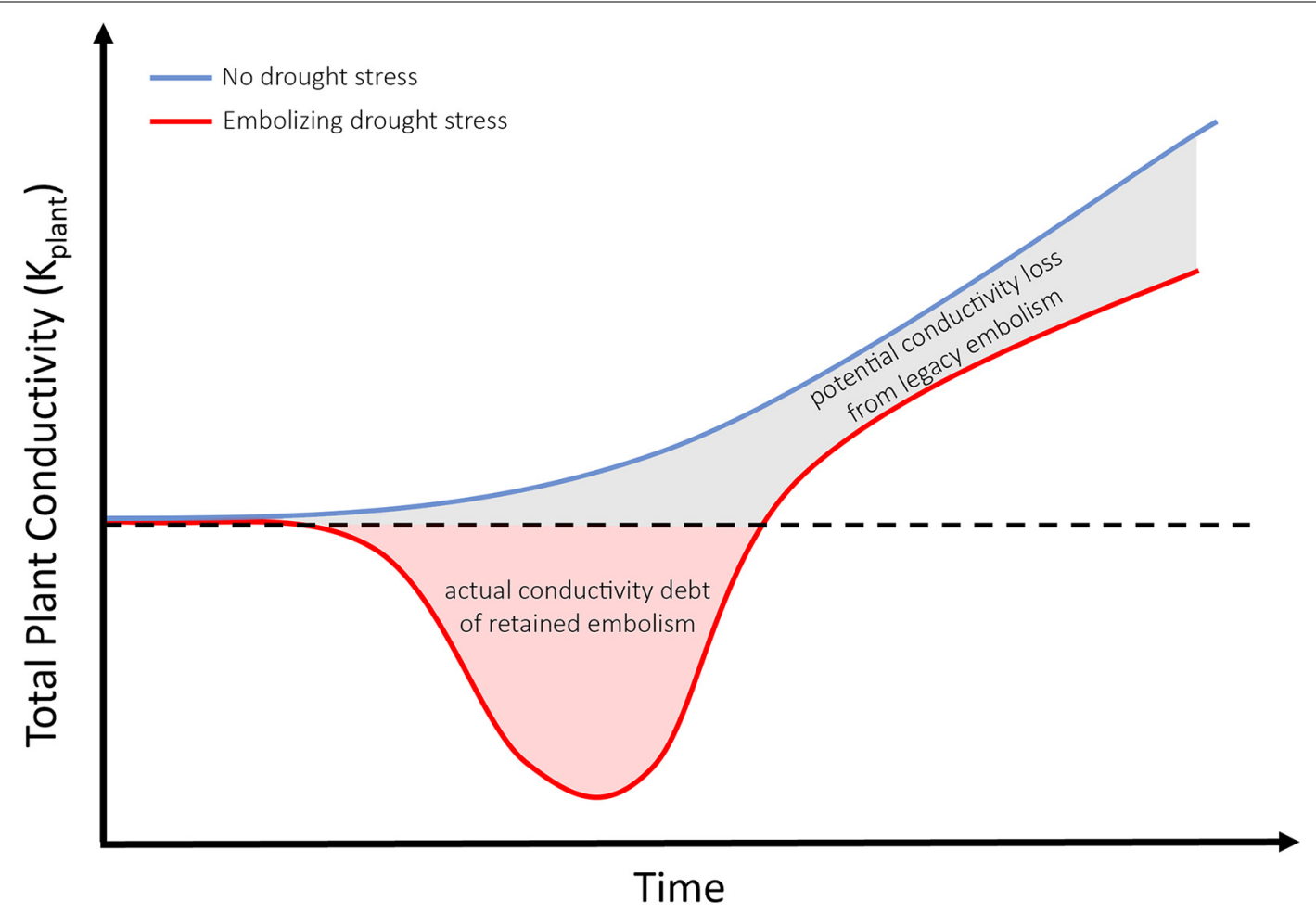

FIGURE 3 | Conceptual diagram comparing the increasing total plant conductivity of a tree that has not experienced embolism-inducing drought stress (blue line) with a tree which has survived drought (red line) and retained significant embolism. Red shading indicates hydraulic debt, or loss of function from pre-drought levels (indicated by the dashed black line). Gray shading indicates the potential conductivity loss from legacy embolism once pre-drought conductivity has been restored via radial growth. 
to increased diversity in hydraulic traits. Increased hydraulic trait diversity within an ecosystem would thus increase ecosystem resilience (Figure 2B, red ball), as not all species within a system would experience catastrophic shifts within their xylem under the same amount of environmental stress; thus reducing the wholeecosystem transition probability for a given set of environmental drivers. An example of diversity's benefit was apparent during recent widespread mortality of pinyon pine (Pinus edulis) in pinyon-juniper woodlands of the southwestern United States (McDowell et al., 2008). Pinyon trees died during hot droughts, but junipers survived. In subsequent years, junipers facilitated (by providing a shaded, cooler, and wetter microclimate) recruitment of pinyon back into the system, a phenomenon known to prevent mortality in recruiting trees (Breshears et al., 2018). In contrast, if junipers were not present, the system may lack sufficient resilience to remain forested as recruitment in the open would be more difficult than recruiting beneath the shady canopy of a mature nurse tree. Similarly phenomena have been documented during globally distributed climateinduced tree mortality events, for example relatively embolismprone Eucalyptus species saw significant mortality during recent droughts in eastern Australia, while more embolism-resistant Callitris species survived (Brodribb et al., 2020).

Finally, trees surviving extreme drought retain the legacy of hydraulic failure (as in Figures 1A, 3), which could reduce resilience across an ecosystem (Figure 2C). The extent to which the increasing resilience from within tree hydraulic diversity (Figure 2A) and within community hydraulic diversity (Figure 2B) can buffer ecosystem resilience decreases due to the legacy of hydraulic failure (as in Figure 2C) is unknown, and of critical importance for future investigations. Common gardens, including urban forests, may provide some insight as study systems, to investigate responses to intensified local microclimates in anticipation of eventually drier and warmer regional climates on natural forests. Presently diverse forests (e.g., warm tropical forests) may experience reductions in diversity as climate continues to warm and dry, while cooler temperate and boreal forests may increase their species and hydraulic diversities as warming makes recruitment of newer species possible.

\section{CONCLUSION AND FUTURE DIRECTIONS}

When it comes to life and death of trees, alternative stable state theory is a useful tool to highlight the catastrophic shifts occurring in xylem tissues of individual trees, and the additive ecosystem-wide effect for potential transitions to alternative states. Transitions from a forested to non-forested state may appear abrupt (Allen and Breshears, 1998; Breshears et al., 2009), yet the underlying conditions of hydraulic function could be changing gradually. As demonstrated in Figure 1A, monitoring physiological drivers like water potential (the most commonly reported indicator of drought stress) is insufficient to detect the hydraulic state of trees which have survived prolonged drought stress resulting in the accrual of embolism in woody tissues. Measuring water potentials even a few weeks after drought's relief would imply healthy, functional water relations when in fact a tree's xylem may have experienced and retained significant levels of embolism. Thus, while there exists some maximum level of perturbation in (temperature, soil moisture deficit) beyond which it becomes more likely that populations of trees composing the forest will die, rather than survive during a single climatic event, we must also consider the legacy of drought (Figure 2C). Using an ASST approach to understand state of xylem within trees provides a framework to include drought's legacy in future models of forest mortality. Models should include both an accounting for the immediate hydraulic debt (actual loss of hydraulic function due to embolism) and the legacy of lost potential hydraulic function had trees not experienced and retained embolism (as in Figure 3). For example, as growth rates and growing seasons of many important forest trees are well described, along with growing databases of species-specific embolism resistance (Choat et al., 2012), future models will be able to account for both the accumulation of embolism under stress, and the long period of growth required to erase the functional debt incurred by this legacy of embolism via regrowth. Emerging evidence suggests the legacy of embolism has severe downstream consequences, as it was found to nearly halve gas exchange rates after drought relief in seedlings of Pinus Sylvestris (Rehschuh et al., 2020). Future work could include an analysis of die-back dependent upon repeated non-lethal drought events, preceding a lethal drought event. Secondary effects of retaining xylem embolism (canopy and fine root die-back) may slow growth, produce less vulnerable xylem in subsequent years of growth, and buffer or offset the perceived cost of retained hydraulic dysfunction. From meta-analysis of empirical data, to hindcasting of known mortality on local to regional scales, including a measure of retained hydraulic dysfunction (as demonstrated through ASST methods here) will enhance our ability to predict the fates of future forests.

\section{DATA AVAILABILITY STATEMENT}

The original contributions presented in the study are included in the article/supplementary materials, further inquiries can be directed to the corresponding author/s.

\section{AUTHOR CONTRIBUTIONS}

WH devised and wrote the manuscript.

\section{FUNDING}

WH was supported by the NSF GRFP (1-746055) and by the Oklahoma Center for the Advancement of Science and Technology Plant Basic Research Program (PS17-006).

\section{ACKNOWLEDGMENTS}

I wish to thank Henry Adams for asking me to consider the intersection of xylem embolism and critical transitions. 


\section{REFERENCES}

Adams, H. D., Zeppel, M. J. B., Anderegg, W. R. L., Hartmann, H., Landhäusser, S. M., Tissue, D. T., et al. (2017). A multi-species synthesis of physiological mechanisms in drought-induced tree mortality. Nat. Ecol. Evol. 1, 1285-1291.

Allen, C. D., and Breshears, D. D. (1998). Drought-induced shift of a forestwoodland ecotone: rapid landscape response to climate variation. Proc. Natl. Acad. Sci. 95, 14839-14842. doi: 10.1073/pnas.95.25.14839

Allen, C. D., Breshears, D. D., and McDowell, N. G. (2015). On underestimation of global vulnerability to tree mortality and forest die-off from hotter drought in the Anthropocene. Ecosphere 6:129.

Allen, C. D., Macalady, A. K., Chenchouni, H., Bachelet, D., McDowell, N., Vennetier, M., et al. (2010). A global overview of drought and heat-induced tree mortality reveals emerging climate change risks for forests. For. Ecol. Manag. 259, 660-684. doi: 10.1016/j.foreco.2009.09.001

Anderegg, W. R., Berry, J. A., Smith, D. D., Sperry, J. S., Anderegg, L. D., and Field, C. B. (2012). The roles of hydraulic and carbon stress in a widespread climateinduced forest die-off. Proc. Natl. Acad. Sci. 109, 233-237. doi: 10.1073/pnas. 1107891109

Anderegg, W. R., Hicke, J. A., Fisher, R. A., Allen, C. D., Aukema, J., Bentz, B., et al. (2015). Tree mortality from drought, insects, and their interactions in a changing climate. N. Phytolog. 208, 674-683. doi: 10.1111/nph.13477

Arellano, G., Medina, N. G., Tan, S., Mohamad, M., and Davies, S. J. (2019). Crown damage and the mortality of tropical trees. N. Phytolog. 221, 169-179. doi: $10.1111 / \mathrm{nph} .15381$

Bar-On, Y. M., Phillips, R., and Milo, R. (2018). The biomass distribution on Earth. Proc. Natl. Acad. Sci. 115, 6506-6511.

Barigah, T. S., Charrier, O., Douris, M., Bonhomme, M., Herbette, S., Améglio, T., et al. (2013). Water stress-induced xylem hydraulic failure is a causal factor of tree mortality in beech and poplar. Ann. Bot. 112, 1431-1437. doi: 10.1093/aob/ mct204

Breshears, D. D., Adams, H. D., Eamus, D., McDowell, N. G., Law, D. J., Will, R. E., et al. (2013). The critical amplifying role of increasing atmospheric moisture demand on tree mortality and associated regional die-off. Front. Plant Sci. 4:266.doi: $10.3389 /$ fpls.2013.00266

Breshears, D. D., Carroll, C. J. W., Redmond, M. D., Wion, A. P., Allen, C. D., Cobb, N. S., et al. (2018). A Dirty Dozen Ways to Die: Metrics and Modifiers of Mortality Driven by Drought and Warming for a Tree Species. Front. For. Glob. Chang. 1:4. doi: 10.3389/ffgc.2018.00004

Breshears, D. D., Cobb, N. S., Rich, P. M., Price, K. P., Allen, C. D., Balice, R. G., et al. (2005). Regional vegetation die-off in response to global-changetype drought. Proc. Natl. Acad. Sci. 102, 15144-15148. doi: 10.1073/pnas. 0505734102

Breshears, D. D., Myers, O. B., Meyer, C. W., Barnes, F. J., Zou, C. B., Allen, C. D., et al. (2009). Tree die-off in response to global change-type drought: Mortality insights from a decade of plant water potential measurements. Front. Ecol. Environ. 7, 185-189. doi: 10.1890/080016

Brodribb, T. J., and Cochard, H. (2009). Hydraulic failure defines the recovery and point of death in water-stressed conifers. Plant Physiol. 149, 575-584. doi: 10.1104/pp.108.129783

Brodribb, T. J., Powers, J., Cochard, H., and Choat, B. (2020). Hanging by a thread? For. Drought Sci. 368, 261-266.

Carlquist, S. (1985). Vasicentric tracheids as a drought survival mechanism in the woody flora of southern California and similar regions; review of vasicentric tracheids. J. Syst. Evol. Bot. 11, 37-68.

Choat, B., Jansen, S., Brodribb, T. J., Cochard, H., Delzon, S., Bhaskar, R., et al (2012). Global convergence in the vulnerability of forests to drought. Nature $491,752-755$

Cobb, R. C., Filipe, J. A., Meentemeyer, R. K., Gilligan, C. A., and Rizzo, D. M. (2012). Ecosystem transformation by emerging infectious disease: loss of large tanoak from California forests. J. Ecol. 100, 712-722. doi: 10.1111/j.1365-2745. 2012.01960.x

Cobb, R. C., Ruthrof, K. X., Breshears, D. D., Lloret, F., Aakala, T., Adams, H. D., et al. (2017). Ecosystem dynamics and management after forest die-off: a global synthesis with conceptual state-and-transition models. Ecosphere 8:e2034. doi: $10.1002 /$ ecs 2.2034

Cochard, H., Cruiziat, P., and Tyree, M. T. (1992). Use of positive pressures to establish vulnerability curves: further support for the air-seeding hypothesis and implications for pressure-volume analysis. Plant Physiol. 100, 205-209. doi: 10.1104/pp.100.1.205

Cochard, H., Damour, G., Bodet, C., Tharwat, I., Poirier, M., and Améglio, T. (2005). Evaluation of a new centrifuge technique for rapid generation of xylem vulnerability curves. Physiol. Plantar. 124, 410-418. doi: 10.1111/j.1399-3054. 2005.00526.x

Cochard, H., and Delzon, S. (2013). Hydraulic failure and repair are not routine in trees. Ann. For. Sci. 70, 659-661. doi: 10.1007/s13595-013-0317-5

Dixon, H. H., and Joly, J. (1894). On the ascent of sap. Proc. R. Soc. London 57, 3-5.

Foley, J. A. (2005). Global Consequences of Land Use. Science 309, 570-574. doi: $10.1126 /$ science. 1111772

Fontes, C. G., Chambers, J. Q., and Higuchi, N. (2018). Revealing the causes and temporal distribution of tree mortality in Central Amazonia. For. Ecol. Manag.424, 177-183. doi: 10.1016/j.foreco.2018.05.002

Givnish, T. (1979). On the adaptive significance of leaf form. Topics in plant population biology. Berlin: Springer, 375-407.

Givnish, T. J. (2002). Adaptive significance of evergreen vs. deciduous leaves: solving the triple paradox. Silva fennica 36, 703-743.

Gonzalez, P., Neilson, R. P., Lenihan, J. M., and Drapek, R. J. (2010). Global patterns in the vulnerability of ecosystems to vegetation shifts due to climate change. Glob. Ecol. Biogeogr. 19, 755-768. doi: 10.1111/j.1466-8238.2010. 00558.x

Hacke, U., and Sperry, J. S. (2015). Functional and ecological xylem anatomy. Berlin: Springer.

Hammond, W. M., Yu, K., Wilson, L. A., Will, R. E., Anderegg, W. R. L., and Adams, H. D. (2019). Dead or dying? Quantifying the point of no return from hydraulic failure in drought-induced tree mortality. N. Phytolog. 223, 1834-1843.

Hogg, E. H., Brandt, J. P., and Michaelian, M. (2008). Impacts of a regional drought on the productivity, dieback, and biomass of western Canadian aspen forests. Can. J. For. Res. 38, 1373-1384. doi: 10.1139/x08-001

Holbrook, N. M., and Zwieniecki, M. A. (2011). Vascular transport in plants. Amsterdam: Elsevier.

Holling, C. S. (1973). Resilience and Stability of Ecological Systems. Ann. Rev. Ecol. Syst. 4, 1-23. doi: 10.1007/978-3-030-54560-4_1

Jardine, K. J., Chambers, J. Q., Holm, J., Jardine, A. B., Fontes, C. G., Zorzanelli, R. F., et al. (2015). Green leaf volatile emissions during high temperature and drought stress in a central amazon rainforest. Plants 4, 678-690. doi: 10.3390/ plants 4030678

Johnson, D. M., Domec, J. C., Berry, Z. C., Schwantes, A. M., Woodruff, D. R., McCulloh, K. A., et al. (2018). Co-occurring woody species have diverse hydraulic strategies and mortality rates during an extreme drought. Plant Cell Environ. 41, 576-588. doi: 10.1111/pce.13121

Johnson, D. M., Wortemann, R., McCulloh, K. A., Jordan-Meille, L., Ward, E., Warren, J. M., et al. (2016). A test of the hydraulic vulnerability segmentation hypothesis in angiosperm and conifer tree species. Tree Physiol. 36, 983-993. doi: 10.1093/treephys/tpw031

Jump, A. S., Ruiz-Benito, P., Greenwood, S., Allen, C. D., Kitzberger, T., Fensham, R., et al. (2017). Structural overshoot of tree growth with climate variability and the global spectrum of drought-induced forest dieback. Glob. Chang. Biol. 23, 3742-3757. doi: $10.1111 /$ gcb.13636

Klein, T., Zeppel, M. J., Anderegg, W. R., Bloemen, J., De Kauwe, M. G., Hudson, P., et al. (2018). Xylem embolism refilling and resilience against drought-induced mortality in woody plants: processes and trade-offs. Ecol. Res. 33, 839-855.

Lamarque, L. J., Corso, D., Torres-Ruiz, J. M., Badel, E., Brodribb, T. J., Burlett, R., et al. (2018). An inconvenient truth about xylem resistance to embolism in the model species for refilling Laurus nobilis L. Ann. For. Sci. 75:88.

Lisenkova, A., Grigorenko, A., Tyazhelova, T., Andreeva, T., Gusev, F., Manakhov, A., et al. (2017). Complete mitochondrial genome and evolutionary analysis of Turritopsis dohrnii, the "immortal" jellyfish with a reversible life-cycle. Mole. Phylogenet. Evol. 107, 232-238. doi: 10.1016/j.ympev.2016.11.007

Maherali, H., Pockman, W. T., and Jackson, R. B. (2004). Adaptive variation in the vulnerability of woody plants to xylem cavitation. Ecol. 85, 2184-2199. doi: 10.1890/02-0538

Matusick, G., Ruthrof, K. X., Brouwers, N. C., Dell, B., and Hardy, G. S. J. (2013). Sudden forest canopy collapse corresponding with extreme drought and heat in a mediterranean-type eucalypt forest in southwestern Australia. Eur. J. For. Res. 132, 497-510. doi: 10.1007/s10342-013-0690-5 
May, R. M. (1977). Thresholds and breakpoints in ecosystems with a multiplicity of stable states. Nature 269, 471-477. doi: 10.1038/269471a0

McCulloh, K. A., Domec, J. C., Johnson, D. M., Smith, D. D., and Meinzer, F. C. (2019). A dynamic yet vulnerable pipeline: Integration and coordination of hydraulic traits across whole plants. Plant Cell Environ. 42, 2789-2807. doi: $10.1111 /$ pce. 13607

McDowell, N., Pockman, W. T., Allen, C. D., Breshears, D. D., Cobb, N., Kolb, T., et al. (2008). Mechanisms of plant survival and mortality during drought: why do some plants survive while others succumb to drought? N. Phytolog. 178, 719-739. doi: 10.1111/j.1469-8137.2008.02436.x

Mora, C., Tittensor, D. P., Adl, S., Simpson, A. G., and Worm, B. (2011). How many species are there on Earth and in the ocean? PLoS Biol. 9:e1001127. doi: 10.1371/journal.pbio.1001127

Negrón-Juárez , R. I., Chambers, J. Q., Guimaraes, G., Zeng, H., Raupp, C. F., Marra, D. M., et al. (2010). Widespread Amazon forest tree mortality from a single cross-basin squall line event. Geophy. Res. Lett. 37:43733.

Phillips, O. L., Aragao, L. E. O. C., Lewis, S. L., Fisher, J. B., Lloyd, J., LopezGonzalez, G., et al. (2009). Drought Sensitivity of the Amazon Rainforest. Science 323, 1344-1347.

Rehschuh, R., Cecilia, A., Zuber, M., Faragó, T., Baumbach, T., Hartmann, H., et al. (2020). Drought-induced xylem embolism limits the recovery of leaf gas exchange in Scots pine. Plant Physiol. 184, 852-864. doi: 10.1104/pp.20. 00407

Salzer, M. W., Pearson, C. L., and Baisan, C. H. (2019). Dating the methuselah walk bristlecone pine floating chronologies. Tree-Ring Res. 75, 61-66. doi: 10.3959/1536-1098-75.1.61

Sanchez-Martinez, P., Martínez-Vilalta , J., Dexter, K. G., Segovia, R. A., and Mencuccini, M. (2020). Adaptation and coordinated evolution of plant hydraulic traits. Ecol. Lett. 2020:13584.

Scheffer, M. (2009a). Alternative stable states and regime shifts in ecosystems. The Princeton guide to ecology. Princeton,NJ: Princeton university press. 809, 395-406.
Scheffer, M. (2009b). Critical transitions in nature and society. Princeton,NJ: Princeton University Press.

Scheffer, M., Carpenter, S., Foley, J. A., Folke, C., and Walker, B. (2001). Catastrophic shifts in ecosystems. Nature 413, 591-596. doi: 10.1038/35098000

Scholander, P. F., Bradstreet, Hemmingsen, E., and Hammel, H. (1965). Sap pressure in vascular plants: negative hydrostatic pressure can be measured in plants. Science 148, 339-346. doi: 10.1126/science.148.3668.339

Schwantes, A. M., Swenson, J. J., and Jackson, R. B. (2016). Quantifying droughtinduced tree mortality in the open canopy woodlands of central Texas. Remote sens. Environ. 181, 54-64. doi: 10.1016/j.rse.2016.03.027

Sperry, J. S., and Tyree, M. T. (1988). Mechanism of water stress-induced xylem embolism. Plant Physiol. 88, 581-587. doi: 10.1104/pp.88.3.581

Tyree, M. T., and Zimmermann, M. H. (2013). Xylem structure and the ascent of sap. Berlin: Springer Science \& Business Media.

Urli, M., Porté, A. J., Cochard, H., Guengant, Y., Burlett, R., and Delzon, S. (2013). Xylem embolism threshold for catastrophic hydraulic failure in angiosperm trees. Tree Physiol. 33, 672-683. doi: 10.1093/treephys/tpt030

Yanoviak, S. P., Gora, E. M., Bitzer, P. M., Burchfield, J. C., Muller-Landau, H. C., Detto, M., et al. (2020). Lightning is a major cause of large tree mortality in a lowland neotropical forest. N. Phytolog. 225, 1936-1944. doi: 10.1111/nph. 16260

Conflict of Interest: The author declares that the research was conducted in the absence of any commercial or financial relationships that could be construed as a potential conflict of interest.

Copyright (C) 2020 Hammond. This is an open-access article distributed under the terms of the Creative Commons Attribution License (CC BY). The use, distribution or reproduction in other forums is permitted, provided the original author(s) and the copyright owner(s) are credited and that the original publication in this journal is cited, in accordance with accepted academic practice. No use, distribution or reproduction is permitted which does not comply with these terms. 